\title{
Surveillance, governmentality and moving the goalposts: the influence of Ofsted on the work of schools in a post-panoptic era.
}

\section{Abstract}

This paper asks the question: to what extent do inspection regimes, particularly Ofsted, influence the work of a school, and how might that influence be conceptualised? It draws on an ESRC funded study of "policy enactments in secondary schools' which was based on case-study work in four 'ordinary' schools. Here the data set is re-examined to understand the extent to which Ofsted had an ongoing influence on the work of the leadership, management and teachers in these schools. We undertook a process of secondary analysis of the data from the project and found that the influence of the inspection agenda was strong in the schools, policy decisions were often being made to conform to Ofsted's expectations and the influence on leadership and management was clearly apparent. In resisting this agenda we also found that schools to some extent performed 'the good school' for inspections. Finally we relate this empirical evidence to conceptions of governmentality and post-panopticism to shed new light on their theoretical relevance to contemporary inspection regimes. 


\section{Surveillance, governmentality and moving the goal-posts: the influence of Ofsted on the work of schools in a post-panoptic era.}

\section{Introduction}

This paper asks the question: to what extent do inspection regimes, particularly Ofsted, influence the work of a school, and how might that influence be conceptualised? It draws on an ESRC funded study of 'policy enactments in secondary schools' (RES- 062-23-1484), which was based on case-study work in four 'ordinary' schools. The aim of the project was to examine how schools enacted policy and it had two main objectives, one theoretical, that is to develop a theory of policy enactment, and one empirical, that is a critical exploration of the differences in the enactment of policy in 'similar' contexts (Ball et al 2011). The data set was generated in four co-educational, non-denominational and non-selective English secondary schools. The schools were moderately successful schools with a sound track record of academic achievement, performing at around the national average.

Here the data are re-examined to understand the extent to which Ofsted had an ongoing influence on the work of the leadership, management and teachers in these schools. Inspection was not the focus of the original research, so any mentions of Ofsted were usually instigated by the interviewees themselves, which may reveal the pervading influence of Ofsted in schools. We undertook a process of secondary analysis of the data from the project and found that the influence of the inspection agenda was strong in the schools, policy decisions were often being made to conform 
to Ofsted's expectations and the influence on leadership and management was clearly apparent. In trying to resist this agenda we also found that schools to some extent tried to perform 'the good school' for inspections. None of this was especially surprising, but we were particularly interested in how these findings worked within ideas about panoptic performativity, governmentality and, more recently, postpanopticism, and it is through exploring these notions empirically that this paper contributes to ongoing debates about the characteristics of inspection regimes.

This paper explains the policy context of inspection in England and outlines our theoretical approach which draws on Foucault's work to view inspection as an aspect of surveillance and of governmentality, and the responses of those subject to inspection as part of technologies of the self, and involving resistance. We then discuss the research context and present the findings to draw conclusions on the applicability of the findings to the latest inspection context and to the conceptual notions mentioned above. To what extent is inspection still about the threat of surveillance as in panoptic models of power, or have changes such as no-notice inspections led to the more pervasive post-panoptic inspection regime as described by Page (2017) and Courtney (2016). And how different is that from panoptic performativity (Perryman 2006)?

\section{Policy Context}

\section{Inspection as surveillance}

The Education Act of 1992 led to the creation of the Office for Standards in Education (Ofsted), which is a privatized inspection system. Inspection teams, who 
have to bid for contracts, are led by a Registered Inspector, and inspect schools according to a criteria-based system. Following the inspection, the Registered Inspector reports to Ofsted and to the school in a publicly available document. The school then produces a summary report for parents and governors and an action plan to address any concerns raised in the report.

At the time of the project, the Ofsted framework in operation was that which operated from 2005-2012 (with minor revisions in 2009). The inspection framework has since changed, but many of the pressures remain the same, and we will discuss the implications for our findings under the current inspection system later. Under the 2009 Inspection framework, schools judged as 'outstanding' or 'good' would receive an inspection every five years, whilst those judged as 'satisfactory' would be visited once every three years. Schools would have one or two days' notice of an imminent inspection, but some schools in the 'satisfactory' category, as well as all schools judged 'inadequate' would have no notice. Importantly for our schools at the time of the research, judgments on the quality of learning gave increased emphasis to attainment, or the standard of pupils' work as shown by test and examination results. OFSTED emphasised that expectations for this aspect of the inspection framework had been raised and that a school could not be 'good' if pupils were not achieving well. As will be shown this emphasis on demonstrating attainment and progress was a clear influence on the work of our schools.

Foucault $(1973,1977)$ argued that institutions become successful insofar as they 'educate' people to accept particular regimes, rather than subject them to coercion. He identified the mechanisms by which this 'education' is achieved as hierarchical supervision, normalising sanctions and examination. In modern institutions such as 
schools, control of the institution is maintained through monitoring and supervision and the constant gathering of knowledge and data about its 'effectiveness'. Not only are pupils being educated in certain regimes, but the teachers and management of the school need to be 'educated' into accepted modes of successful practice. Inspection plays a key supervisory role in this discipline, and sets the agenda by which successful practice is measured, which is a form of normalisation.

Normalisation, which involves the modification of behaviour to come within socially acceptable standards, is a powerful mechanism of power, which is achieved through the hegemonic internalisation of discourses of control. In general, this means that those who are subjects of power internalise expected behaviours, and learn these behaviours through acceptance of a discourse. In an inspection context, normalisation describes the processes by which schools come to operate within the accepted norms of an 'effective school', whether or not they are actually being inspected.

In terms of inspection, the term 'panoptic performativity' (Perryman 2006) can be used to describe the way that teachers can experience inspection regimes as if they are constantly being observed, subjected to a seemingly relentless gaze, and perform accordingly in order to be successful. Troman (1997: 349) puts it like this; 'inspectors are the absent presence in the school'. Inspection can seem a constant threat, particularly for those schools identified following inspection as 'requiring improvement', and teachers can modify their behaviour in a more permanent way 'because the constant pressure acts even before the offences, mistakes or crimes have been committed' (Foucault 1977: 206). During Ofsted inspections, 'the nature of the audit influences performance, and schools change their practices to conform to what they think the inspectors inspect' (Earley, 1998: 172). However, the term 'panoptic 
performativity' can also be employed under current inspection practices, particularly those with short- or no-notice warnings, meaning that schools do not know when they are to be inspected, and thus to be 'safe' they must work within a constant state of 'inspection readiness'. Our data will examine how in our schools policies and procedures were conducted under the perceived threat of inspection, and the constant feeling of being under surveillance.

Under panoptic performativity, inspection is not just about external surveillance. It is through the in-school culture of performativity and accountability that conformativity, discipline and normalisation is achieved, as teachers learn to police themselves, and to perform the successful inculcation of the normalised behaviour. As Harland (1996: 101) notes, 'the exercise of continuing surveillance through the process of monitoring and evaluation means that those concerned also come to anticipate the response...to their actions past, present, and future and therefore come to discipline themselves'. Thus a school becomes 'an organisation for 'the gaze' and for the avoidance of 'the gaze" (Ball, 1997: 332). As the changing inspection frameworks have increasingly emphasized the role of schools in maintaining the gaze it could be argued that this focus ensures the permanence of the performing school, inspection as governmentality. The performative culture is so deeply ingrained in English schools and education systems there is now a game of permanent artifice, where schools hold themselves in a state of perpetual readiness to live up to their claims, the model prisoner (Perryman 2006). The panoptic metaphor remains relevant to current inspection regimes, but perhaps the notion of governmentality is also apt, especially in the case of the 'ordinary schools' (Maguire et al 2011) which were the subject of this research. 


\section{Inspection as Governmentality}

Foucault used governmentality to describe a range of procedures and techniques used to guide and control conduct. In these terms 'government' is not just about national and local political control, but also refers to the self, so is also how and why the self shapes its own conduct in particular ways. Governmentality, according to Foucault (2008: 147), creates homo aconomicus, 'the man of enterprise and production'. He describes this new human as the 'entrepreneur of himself, being for himself the source of [his] earnings' ( $p$ 226). Whilst the governmentality of school leadership is about shaping one self and others' conduct, technologies of the self lead to people influencing themselves and each other in more subtle ways.

In The Care of the Self (1988), Foucault described how individuals were made subject to codes of ethics and behaviour and discussed 'forms of elaboration' which mean that individuals either follow rules, or are converted to a certain way of behaving. Individuals follow a set of practices, 'techniques of the self', which enable them to be in control, and may believe this control comes from within rather than externally. They believe themselves in need of change:

The practice of the self implies that one should form the image of oneself not simply as an imperfect, ignorant individual who requires correction, training and instruction, but as one who suffers from certain ills and who needs to have them treated either by oneself or by someone who has the necessary competence (Foucault 1988: 57).

In this way, according to Ceplak (2012: 1096) 'neoliberal educational reforms and 
pedagogical discourse on the autonomous and self-governing individual enable the effective operation of 'soft power' and the emergence of a society of control based on self-control'

In the context of this paper, we argue that rather than being controlled and disciplined, senior leaders and teachers position themselves in particular ways to act upon their own conduct in order to fit the system, and adapt to changing policy contexts such as changing inspection frameworks - 'the self working on the self, the self shaping its own conduct' (Gillies 2013: 79). In this context, Ofsted is a more hidden power than that described above, working as a subtle influence on school practices and normalities such that inspection does not have to physically take place for a school to be governed by its perceived judgements.

It is in this context that the notion of post-panopticism becomes relevant. Postpanopticism has arisen as a counterpoint to and criticism of Foucauldian notions of panopticism. Panoptic performativity took the panoptic metaphor and linked it to notion of performativity. This meant that inspection was not just about surveillance, but the threat of surveillance, and engendered a regime in which schools self-govern their performance. Post-panopticism arises from the idea that playing the game of panoptic performativity leads to simulation. As Bogard (1996: 66) argues

The figure of the Panopticon is already haunted by a parallel figure of simulation. Surveillance, we are told, is discreet, unobtrusive, camouflaged, unverifiable - all elements of artifice designed into an architectural arrangement of spaces to produce real effects of discipline. Eventually this will lead, by its means of perfection, to the elimination of the Panopticon itself 
... surveillance as its own simulation. . . Now, one can simulate a space of control, project an indefinite number of courses of action, train for each possibility, and react immediately with pre-programmed responses to the actual course of events ...

Courtney (2016: 627) identifies six characteristics of panoptic regimes - permanent visibility, clear expected norms, a goal of compliance with these norms, demonstration of compliance (which may lead to gaming), self-policed fabrication, and market compliance. He contrasts this with the characteristics of post-panopticism in inspection;

The first is conscious, total visibility to all. Second, the 'norms' it imposes masquerade as such, but are purposively in flux, transient and fuzzy. Consequently they are not norms at all, although it is discursively constructed that they are, and that activities relating to them must be performed as though they are. Third, the goal of post-panopticism is to expose subjects' inevitable failure to comply. Fourth, its consequence is to disrupt subjects' fabrications that had been predicated on stability. Fifth, it is dependent on external 'experts' to produce success criteria. Sixth, its effects are experienced differentially; it adopts the discourse of the market to promote a (neo)conservative agenda devalorising the interests of the socio-economically disadvantaged (Courtney 2016: 627).

In terms of this paper, the characteristics we can explore through our data are the notions of conscious and total visibility, and 'fuzzy norms'. Page (2017: 4) argues that 
conscious and total visibility exists as changes in technology and in social norms have led to the democratization of and willing participation in surveillance 'permitting the surveillance of everyone, not just specified groups, and not just for specific reasons data are collected on everyone as routine'. Page argues that due to the high-risk status of inspections for school leaders 'where once surveillance was temporal, focused on specific times and activities, teachers now work within an environment of normalised visibility’ (Page 2017:4).

This theoretical context provides a useful lens through which to re-examine data previously gathered. To what extent, we wondered, was Ofsted as a hidden power governing the work of these schools? Inspection was not a focus of the data gathering, yet how often was it mentioned as an influence, a fear, a system under which schools lived? Was Ofsted primarily a vehicle for periodic surveillant visits which needed to be prepared for, or more subtly a set of rules by which school leaders and teachers lived, having been inculcated into a certain way of thinking? And if so, does this provide evidence for post-panoptic inspection regimes?

\section{Research Context}

The data set was generated in four co-educational, non-denominational and nonselective secondary schools which were selected as described elsewhere for their 'ordinary' profiles (Maguire et al 2011) and were either 'good' or 'satisfactory' according to Ofsted and performing at around the national average in terms of School Performance Tables at the time of our data collection. The sample included Atwood School, a community school in central London; two more in suburban education 
authorities, George Eliot and Wesley School; and a fourth, Campion School, located in a smaller county town. (All these school names, and the names of our respondents, are pseudonyms). As the project commenced and developed over the two and a half year period of its duration, we collected documentary evidence from the schools and observed training sessions and briefings, in which policy was disseminated and reworked. The substantive body of data on which this paper is based is the 95 semistructured interviews conducted with head teachers, senior management, teachers, union representatives and support and advisory staff.

Secondary analysis involves using data previously collected for an earlier study. Heaton (1998:3) suggests three forms of this, over different types of data sets; additional in-depth analysis, additional subset analysis, and new perspective conceptual focus. The last category is employed here, i.e. 'the retrospective analysis of the whole or part of a data set from a different perspective, to examine concepts which were not central to the original research'.

Secondary analysis may distance the researcher from the original research. But as Heaton (1998: 5) argues, even when primary data have been collected the researcher may not have been working alone, nor transcribed the data and

a more radical response is to argue that the design, conduct and analysis of both qualitative and quantitative research are always contingent upon the contextualization and interpretation of subjects' situation and responses. Thus, secondary analysis is no more problematic than other forms of empirical inquiry, all of which, at some stage, depend on the researcher's ability to form critical insights based on inter-subjective understanding. 
Procter (1993:256) remarks 'it is a truism of social research that almost all data is seriously under-analysed: unless the data collection is tightly designed to test a specific hypothesis, the original researcher will explore only a fraction of its potential'. This paper outlines the findings of a secondary analysis of data. We subjected the data set to further analysis using NVIVO to search for Ofsted and inspect* (to allow for inspection, inspectors etc.). The data set was then analysed using a system of open-coding based on Braun and Clarke's (2006) thematic analysis and involved refamiliarising ourselves with the data, generating initial codes, searching for themes, reviewing for themes and finally categorising and naming them.

\section{Findings}

We now examine the findings in detail, looking in turn at the influence of Ofsted on leadership and management, how Ofsted influences policy making in school more broadly (and the extent to which that implies surveillance or governmentality and whether the context is now post-panoptic), and whether there is an element of resistance, through performance and game-playing in schools' relationship to inspection.

Ofsted and the agency of school leaders.

Sammons, Hillman et al. (1995: 8-11) identified professional leadership as one of the most important characteristics of a successful school, reporting that there was little evidence of effective schools that had a weak leadership team. Professional leadership involves strength of purpose, involving other staff in decision-making, and professional authority in teaching and learning. "The research evidence consistently 
demonstrates that the quality of leadership determines the motivation of teachers and the quality of teaching in the classroom' (Harris et al., 2006: 121).

However, an accountability culture can affect the agency of head teachers, as Evans (2001: 151) explains: 'at the same time as heads are being trained for leadership and vision and a mission for the school, they are simultaneously in receipt of education policies that are extremely instrumental and interrupt their own agency as head'.

As one of our respondents noted:

Rather than... getting it done to them all the time, which is kind of contradictory to what's meant to be a devolved management, self-managing school and all the rest of it [inaudible] a deep contradiction there: you can manage your own school but you have to do it this way, you know, and if you don't we're going to hit you with a big stick called Ofsted. (Clare, middle manager $^{1}$, Campion)

There is nothing subtle about the 'big stick' here. However, with the increase in the power of Ofsted via short notice inspections, Page (2017:5) argues that using Ofsted for management purposes has changed from the 'big stick' that Clare mentions to more of a constant background hum;

Times have changed: with Ofsted giving almost no notice of inspection, head teachers commit to continual Ofsted-readiness within their schools, a perpetual state of inspection anxiety that aims for good-or-outstanding practice

\footnotetext{
${ }^{1}$ All respondents have been described in broadest possible terms to prevent identification of individuals
} 
throughout every day, every week and every year.

Page's work describes the current English Ofsted context, but this intensification, this process of needing to be 'Ofsted-ready' was evident in our earlier study (Ball et al 2011) as senior management in our schools employed techniques such as 'Learning walks', training and observation to improve teaching and learning and ensure a state of inspection readiness.

However, the view that external monitoring and surveillance can disempower head teachers is at odds with the argument that, particularly in challenging schools, they may use the threat of external intervention for their own purposes. We also found that head teachers were using Ofsted as a way to pursue unpopular policies, positioning it very much as the external enemy. James (1999: 150) writes that: 'in schools ... change may be brought about by using external 'enemies' such as league tables of examination results [and] school inspection...'. Similarly, Chapman (2002: 261), in a case study of teachers' perceptions of Ofsted conducted in ten secondary schools, was told by one head teacher: 'in some circumstances it's difficult to galvanise your staff into action. Now if you need that tool, if you need that power, then it (Ofsted) gives you that'.

Ball (1997: 332) noted of one school under inspection that:

the locus of power or blame for additional work, overbearing paperwork, meticulous surveillance was often located with OfSTED and not directly with the senior management team who frequently positioned themselves as ciphers for outside pressure. 
An example of this use of the 'external enemy', which undoubtedly falls under the surveillant category of Ofsted's power, comes from Naomi who said of the headteacher;

And he started his presentation by saying, "Obviously it's a contentious issue, so I'm not saying it's not controversial, but this is what we have to do for Ofsted," which I think was as near as he was going to get as a head to saying, "It's controversial and I don't like it." [The head] was more diplomatic but other members of [the senior leadership team], when they were presenting it to us, basically said, "We don't like this but we're on the list for a no-notice inspection, we only got a 'satisfactory' last time, we were 'good' before, we're going to have to do it anyway" (Naomi, teacher, Atwood).

Here the senior leadership team position themselves as in opposition to the demands of inspection, but subject to it, possibly a clever tactic deflecting from their own pursuance of unpopular policies. Indeed, some of the managers interviewed talked favourably about Ofsted as impetus for school improvement, demonstrating that the threat of inspection can act as an internal driver for improvement.

We then got put into 'notice to improve'. And I'd been on the SLT for about six months when we got put into it and I went, 'Fantastic'. And people looked at me, and one of the county advisors was in there, and I said, 'We've just got this momentum going to get this school back to where we want it'. If we got 
classified as 'satisfactory', people would take their foot off the gas, we'd stop there (Fiona, senior leader, Campion).

[The staff] couldn't believe that we weren't a good school, that we were what was then Ofsted category five, which meant that we were an underachieving school. And that was a, you know, it was a really good thing that we had that Ofsted report because it did challenge those perceptions, it did enable us to really start moving things forward (Hazel, senior leader, Wesley).

We had a bad Ofsted and, you know, we weren't put into special measures but I think we only just avoided special measures, so that really galvanised everybody into wanting to make improvements (James, senior leader, Wesley).

So it appears that in our schools, in terms of management techniques, the discourse of Ofsted was deployed in two ways. The threat of inspection could be used to create an external enemy and drive forward unpopular policies and it was also welcomed by some senior leaders as an impetus for improvement or at least proof of the need for change.

We found that Ofsted was also used by management as a validation of perceived good practice.

Ofsted, you know, we had a good Ofsted. So, you know, that's, I suppose, validated some of the things we've been doing. Our own internal monitoring, 
well, that's another thing that we do now that we didn't used to (James, senior leader, Wesley).

So far, in terms of its effects on leadership in general, Ofsted was not a subtle hidden influence. It was affecting the agency of leaders, but at the same time the threat of its presence was being used by them. This is a very panoptic, disciplinary top down notion of inspection. The next section looks at this in more detail, as the Ofsted agenda influenced the prioritization of policy.

\section{Identifying policy priorities according to Ofsted}

One of the most common themes in the data was that the leadership teams in our schools identified many of their policy priorities according to Ofsted requirements. In our schools there was a definite sense that Ofsted's agenda, as detailed in their framework for inspection was, to some extent, driving the response to policy; if it was valued, and was to be judged by Ofsted, then it would be valued by the school. This is echoed by Gustaffson et al (2015:48)

Schools are expected to attend to the requirements included in inspection standards and procedures and adapt their goals and ways of working to come into line with the normative image of high quality schools demanded by the inspectorate. These inspection frameworks are designed to inform and drive school policy, planning and practices.

Keddie (2013: 21) agrees, saying that whilst some 'high performing schools...can adopt the policies of the audit culture without changing their core beliefs or dynamics...other lower performing schools may need to radically alter their beliefs 
and dynamics to fit with performative demands'.

What tends to happen is if it's not valued by Ofsted or by, you know, I don't know, say if it's important to the headmaster, then it'll just sort of disappear altogether. If it is valued by Ofsted, or somebody else, we'll then have one of these sort of insane periods where suddenly, you know, you'll be put under enormous pressure to make sure you're doing lesson observations (Gareth, middle manager, Campion).

This sense of Ofsted driving policy was ratcheted up when it was thought that an inspection was due. The notion of no-notice inspection works in theory, but in reality the timing of previous inspections, or inspection activity within the borough can lead to schools being able to predict quite accurately the timing of the next inspection.

We knew there was going to be another inspection in a couple of years so there's this policy overload. Because we had a new head in, a couple of - I think they had new deputies as well and we did, you know, two/three years we just had policy after policy after policy after policy (Robert, middle manager, Wesley)

So I think the first thing was to look at - to get ourselves out of "notice to improve'. So what do we do have to do? And then there was an Ofsted inspection looming, if you like, within that. So the focus was quite literally Ofsted, you know... (Clare, middle manager, Campion)

Often the most pressing concerns expressed were about attainment levels. This is 
unsurprising as Ofsted increasingly uses attainment results as the first step in an inspection. The effects of this can lead to an increased emphasis on data as Lawn et al (2015: 96) point out

Data arrive in schools in different ways but however they arrive, they have a direct power over them. The school can appear to rise or fall, or become visible or invisible, through data and their effects. While data focus on performance and comparison, they displace and destabilise the school, placing it in relation to other producers at great distance, and reshaping careers and choices.

In our schools, especially in the high stakes subjects of English, Science and Maths, there was an emphasis on attainment and this was linked to concerns about the Ofsted agenda

So it's a bit of an uphill struggle sometimes and really the underachievers at Key Stage 4 are more of a priority for the school and so they should be, obviously, because that's really the data that Ofsted are interested in (Ewan, middle manager Campion).

I think there are a number of outside levers, if you like, which would be Ofsted, it would be about [results] in English and maths... (Catherine, senior leader, Atwood).

I think, yeah, we're under a lot of pressure, especially here at the moment. We've just had an Ofsted early on in September so this drive to get these A- 
star to $C$ at the moment is huge. So there is this push, there is a pressure to get it now (Molly, teacher, Campion).

The attainment focus has led schools to adopt a results-driven approach, with a plethora of strategies aimed at improving results. These include Easter and Saturday revision classes for students about to take public examinations, targeting students on the $\mathrm{C} / \mathrm{D}$ borderline to increase the numbers of students achieving five $\mathrm{A}^{*}-\mathrm{C}$ grades in GCSE examinations, regular interviews of 'under-achieving' students by senior leadership teams, and timetabling for intensive revision classes. The main driver behind these 'interventions' is to increase the numbers of students achieving five $\mathrm{A}^{*}$ $\mathrm{C}$ grades in GCSE examinations, the key national public indicator at the time of school performance as reported in English league tables.

Another theme that emerged from the secondary data analysis is that aside from the main priority of demonstrating improved attainment, issues chosen for development by the schools were those picked up in a previous inspection;

Yeah, part of the things from[the previous] Ofsted were about making lessons more active, about engaging students more in their learning and that was something that Ofsted said from lessons that that's what they saw that the students tend to be quite passive (Caroline, senior leader, Atwood).

So we will be planning the next staff conference, which will be very much the two targets for marking, that's a big thing, and Assessment for Learning, 
challenging our children a lot more. And that's obviously come up in Ofsted as well recently, so we're...(Alice, middle manager, Campion).

There's a big impact in terms of AFL [Assessment for Learning], which is probably one of our weaker areas. And I think that was picked up in our Ofsted report as well (Laura, middle manager, George Eliot).

There was a sense that schools were preoccupied with being prepared for Ofsted's next visit. What Perryman (2006) describes as 'the permanent panopticon' is echoed here.

When [middle managers] have joint meetings they're just very engineered by senior management to talk about whatever it is that are wider school issues. And it's really about Ofsted, making sure that we're all ready for Ofsted again. I think that's really that it's about (Beth, middle manager, Atwood).

There's also a concern that, you know, just in the local context, eight of the nine schools are due to be Ofsteded next year and so, under the new framework, you know, what was 'good' might be 'satisfactory'. And so they are concerned about, well, progress, what does progress look like in a lesson and how can we go from 'good' to 'outstanding' (Patricia, middle manager, Atwood).

This is where we can see a move from panoptic performativity with its norm certainties to the 'fuzzy norms' (Courtney 2016) of post-panopticism. Patricia here 
shows concern about coping with whatever changes Ofsted has emphasised with the introduction of a new framework for inspection, a sense of confusion about 'moving goalposts' that Courtney (2016: 624) argues is deliberate:

Post-panopticism in school inspection is designed to wrong-foot school leaders, disrupt the fabrications they have constructed to withstand the inspectors' gaze, and make more visible the artifice of the performances that constitute their identities.

Schools cannot set themselves up to be 'Ofsted proof' and then rest on their laurels. Courtney (2016: 631) gives the following example of changing emphases across the frameworks:

For instance, a school with average attainment, excellent $\mathrm{CVA}^{2}$, very good teaching, outstanding pupil care and a focus on community cohesion could conceivably receive an 'outstanding' rating in 2011. From January 2012, this school would have to change its focus to producing better VA results, possibly at the expense of its de-privileged community work, to retain its status. From September 2012, its emphasis must change again to demonstrating outstanding teaching.

Whether a deliberate policy (as Courtney suggests) or not, this idea of the shifting of the goalposts was echoed by our respondents, and reflects the emphasis at the time on attainment and data at the time of our study.

2 Contextual Value Added - a measure of pupil's progress which takes into account their circumstances 
Ofsted said they'd be back in two or three years... and they came back and I was shocked, they'd moved the goalposts, it wasn't the same type of inspection. Their focus was more on other things than the things that we had tried to improve. So we'd tried to improve by their action plan and their focus had changed and nobody had told us that the focus had changed, so we went deeper down the ladder (Douglas, middle manager, Wesley).

In our last INSET a couple of weeks back, the new Ofsted framework... came in, particularly focus on raw data rather than contextually value-added, which is going to have implications for who we focus on in terms of intervention and things (Naomi, teacher, Atwood).

In these examples from the data we see that there is a sense of the 'fuzzy norms' Courtney describes. These have been developed, as he argues above, to disrupt the game-playing that can be the response to inspection regimes. Given this, and as no Foucauldian analysis is complete without a discussion of resistance to power, how much of our data was about game-playing and putting on a show?

\section{Gaming}

Power is exercised only over free subjects, and only insofar as they are free.

By this we mean individual or collective subjects who are faced with a field of possibilities in which several kinds of conduct, several ways of reacting and modes of behaviour are available (Foucault, 1994: 132). 
In schools, resistance to a technology such as performativity is not easy, as it is so rooted within the discourse of what is important, and those in power will often be the defenders of the discourse as we have seen in our data. Bennett (2003: 53) explains that:

In organisational settings, the power which drives and shapes the cultural and structural constraints on individual action is exercised by individuals 'cultural players' who possess particular forms of power resources which they have acquired by first accepting particular norms and then developing, articulating and sustaining a particular interpretation of them.

The performance presented by a school undergoing inspection is usually set within the parameters governed by the discourse around what constitutes a good school as set out in the inspection framework. Changes of behaviour can be seen in the fabrication of documentation, staging and game-playing before and during inspection, and in a new era of post-panoptic inspection performance can be a permanent artifice.

Ball (2003: 8) remarks that under inspection 'what is produced is a spectacle or what we might see as an 'enacted fantasy' which is there to be seen and judged'. He goes on to say that 'the heart of the educational project is gouged out and left empty. Authenticity is replaced by plasticity'. This argument that schools perform rather than demonstrate reality is echoed elsewhere. For example in Chapman's (2002: 261) research, teachers told him that OfSTED had failed to pick up on many important issues for the school: 
Senior teams reported that they attempted to minimise their vulnerability to variability of inspection teams or poor timing of an inspection through rigorous planning and thorough preparation of staff... One middle manager reported 'they are critical times for the head and he will do everything in his power to present the school in the best light'.

Similarly, Burns (2000: 26), interviewing teachers in schools which had just undergone OfSTED inspections, found responses such as, 'I think OfSTED week was like a performance...a play and we acted very, very well...it wasn't the real school'. In another example, a deputy head told Jeffrey (2002: 543) that 'you have to actually catch on to what it is they want... and then perform it'. One head teacher told Plowright (2007: 382) 'we'd trained our staff well. I used one or two tricks that I knew would go down well'.

De Wolf and Janssens (2007: 382) found that 'gaming' or 'intended strategic behaviour' as a response to inspection is not unusual

The most well known form of intended strategic behaviour is 'window dressing'. This means the creation of proactive and reactive arrangements which are generated simply and solely to be assessed more favourably by the supervisor

One way of gaming can lie in the training and preparation for inspection. We found much evidence of this in our schools. 
You know, we had one just a few weeks ago on the new Ofsted framework, breaking down all the new observation framework... so that we can start to look at the observation framework (Heather, senior leader, Atwood)

Just one, you know, brief example if it helps, but like a lot of schools we're, you know, asking people to come in to give us pre-Ofsted checks, particularly with the Safeguarding ${ }^{3}$ issue. (Ken, senior leader, Atwood)

There is indeed a whole industry built up around Ofsted preparation (Espinoza 2015) and our schools were not unusual in hiring experts to help them prepare. It is important to note again that our interviews were not directly focusing on inspection, nor undertaken at a time when inspection was imminent, so the fact that being prepared for Ofsted, in a permanent way was discussed indicates how much it has become part of the ongoing fabric of the schools, inspection as governmentality.

Thus there was much talk of the need for building up evidence for Ofsted and the phrase ‘tick boxes' was oft repeated.

But I think at Campion what we do well is, sort of, tick boxes, you know, if Ofsted came in would we have a bit of paper showing that we've done this? Yes, you know, we would (Gareth, senior leader, Campion).

\footnotetext{
${ }^{3}$ Schools have a statutory duty to protect children in their care through safeguarding
} 
So when we put that time and effort in we don't follow it up. That's it, that's finished, that's gone. It's almost ticking the boxes so we can say to Ofsted we've done it (Manuel, senior leader, Campion).

So whatever way but get it put in place so the box can be ticked and so we've addressed this issues, we've addressed this policy (Neil, middle manager, Wesley).

This sense of box-ticking and hoop-jumping explains why undergoing inspection is still seen in terms of a performance. As Molly, (teacher, Campion) puts it 'but, you know, you do put on a show for Ofsted, it's not real'.

And at the end of the day as well, I mean, most people, even the public know the day when Ofsted come in things are different. You know, you've got to look at the quality of provision over a long period of time. Everyone can teach an 'outstanding' lesson when they're being observed if they have to. If they can't then that is a bit of a worry (Joe, middle manager, Atwood).

This rather inevitably leads to cynicism about things being done just for Ofsted

The other thing with the observations is it breeds an Ofsted mentality, it's pressure, and the focus isn't necessarily on the quality of teaching and learning and attainment, it's on passing the lesson observation, it's getting the good grade (Manuel, senior leader, Campion). 
Some teachers expressed frustration with this state of affairs and made a plea for putting the genuine needs of the school first

Make the decisions that best fit the needs of the students, the parents of that community, rather than being forced from above to fit into certain boxes and have every school running this kind of program within it, etc. and having to customise it to fit your school and squeeze it in there to be seen to be doing it when Ofsted arrive (Joe, middle manager, Atwood).

And we have an Ofsted coming up. And, for me, I don't want Ofsted to become a driver. I want us to be able to have the integrity to say our main driving force is children learning, children achieving, because that's what we're here for, that's our core purpose. Ofsted is an external pressure but it isn't the driving force (Lesley, middle manager, Campion).

Much of what we have discussed here perhaps indicates that Ofsted is indeed a driving force despite Lesley's remark. Both with the permanent threat of inspection (surveillance) and ongoing normalisation of practice (governmentality) Ofsted is undoubtedly a significant influence on how schools work, and in the post-panoptic era the lack of predictability of expected norms makes the influence more subtle and more pervasive and the 'game' of panoptic performativity harder to play.

\section{Conclusion}

This paper is based on research carried out before the most recent changes in the 
inspection framework. There have been revisions since, notably in 2012 and 2015. The 2012 model of inspection reduced the number of judgements made by inspectors from 29 to just four, and the category 'Satisfactory' was replaced by the category 'Requires Improvement'. As Baxter and Clarke (2013: 706) explain 'the replacement of this category with the 'requires improvement' judgement is designed to reflect more rigorous standards in school inspection and to act as a catalyst for school improvement'. In other words, it was decided that an inspection regime could not claim to be improving schools if schools remained 'merely' satisfactory in successive inspections. This would presumably add to the pressures described throughout this paper, particularly for schools in the 'satisfactory' category. The 2015 framework introduced a common inspection framework across all sectors of education, and introduced four judgement areas: Effectiveness of leadership and management; quality of teaching; learning and assessment; personal development; behaviour and welfare; and outcomes for children and learners. The emphasis on school selfevaluation, the pre-eminence of pupil attainment as an indicator of success, and little or no-notice periods remained the same as for the period of research.

These changes have made inspection regimes increasingly post-panoptic. Courtney (2016:632) argues that

Compliance is woven so tightly into the regime's fabric that head teachers are unaware that performance 'on the day' is thereby replaced by a longer-lasting and more deeply affecting fabrication. This, however, is a post-panoptic regime in which the scrutiniser forces continual re-normalisation by obscuring those norms through multiplication. 
Page (2017: 2) suggests that this leads to an element of risk management in how schools approach policy

With risk the primary driver of surveillance in schools, traditional surveillance - the panoptic - has been rendered obsolete. . the panoptic is reactive, observing before judgement in the present tense. With future risk the driving force in the contemporary school, what is needed is a means of prediction, of knowing the future as if it had already past, a means of avoiding and eliminating risk. Here is the notion of surveillance as simulation

The concept of post-panopticism is evidenced within our data, and if data were gathered at the time of writing then there would probably have been even more evidence of unpredictability and the moving of goalposts .

This paper set out to explore how Ofsted is a behind-the-scenes influence on schools and their management teams. Evidence from four 'ordinary schools' would suggest that Ofsted is at the forefront for leaders and management. It could be argued that for some it disrupts agency, but we did find examples of head teachers using the threat of an external enemy and a looming Ofsted visit to drive through unpopular policies, or embed systems into the fabric of the school which otherwise may have been resisted. It was also welcomed by some leaders as the impetus for improvement, and used as vindication to justify certain practices. Almost a decade ago, writing about inspection in schools under Special Measures (Perryman 2006), one of us wrote that the head teacher and senior management of the school, once the school was released from the regime, continued the rigorous discipline experienced under inspection and replaced 
external disciplinary sources with internal mechanisms, a highly visible management team, a continuing programme of lesson observations and a drive for innovation and change. This, it would appear is now the norm in our 'ordinary schools', a perception of post-panoptic perpetual readiness for inspection.

This does not mean that performing for inspection no longer occurs, but perhaps is less obvious - or is it less obvious what needs to be done? With no- and little-notice inspections schools must be careful that they are inspection ready. Before the change in notice period, research (Perryman 2009) shows that in some schools documentation was enhanced, lesson plans created, pupils temporarily disappeared. Briefings were rehearsed, displays embellished, and meeting records amended. A distorted, yet successful school was presented to inspectors, who wrote their report accordingly. In the post-panoptic school the veneers of success to demonstrate to the inspectors are likely to be present all the time, and teachers will be rehearsed, trained and inculcated in Ofsted friendly 'effectiveness' in a permanent way. The performance is less obvious, but now involves prioritising policies according to the perceived (and everchanging) Ofsted agenda and ensuring that 'boxes are ticked'. Cynicism about the process is evident, as well as frustration that sometimes the genuine needs of the school are sidelined. In providing empirical support for the concept of post-panoptic inspection regimes this paper sets the agenda for future research in the area. 


\section{References}

Ball, S. (1997) Good School/Bad School: paradox and fabrication, British Journal of the Sociology of Education, 18(3), 317-336.

Ball, S. (2003) The Teacher's Soul and the Terrors of Performativity, Journal of Education Policy, 18(2), 215-288.

Ball, S, Maguire, M and Braun, A with Hoskins K and Perryman, J (2011) How Schools Do Policy: Policy enactments in secondary schools (London, Routledge)

Baxter, J and Clarke, J. (2013) Farewell to the tick box inspector? Ofsted and the changing regime of school inspection in England, Oxford Review of Education, 39(5), 702-718.

Bennett, N. (2003) Structure, Culture and Power in Organisations, in: N. Bennett, M. Crawford \& M. Cartwright (Eds) Effective Educational Leadership (London, Paul Chapman).

Bogard, W. (1996) The Simulation of Surveillance, Cambridge: Cambridge University Press.

Braun, V. and Clarke, V. (2006) Using thematic analysis in psychology, Qualitative Research in Psychology, 3 (2), 77-101

Burns, J. (2000) Improvement through Inspection'? An investigation of teachers' perceptions of OfSTED as a vehicle of improvement (University of Central England, Oakhill)

Ceplak, M. (2012) The individualisation of responsibility and school achievement Czech Sociological Review, 48 (6), 1093-1114

Chapman, C. (2002) OfSTED and School Improvement: teachers' perceptions of the inspection process in schools facing challenging circumstances, School Leadership and Management, 22(3), 257-272.

Courtney, S.J. (2016) Post-panopticism and school inspection in England, British Journal of Sociology of Education, 37(4), 623-642

Cullen, J.B. and Reback, R. (2006) Tinkering toward accolades: school gaming under a performance accountability system (Cambridge: National Bureau of Economic Research). Working paper 12286. http://www.nber.org/papers/w12286. Accessed Nov 2016.

De Wolf, I.F. and Janssens, F.J.G (2007) Effects and side effects of inspections and accountability in education: an overview of empirical studies. Oxford Review of Education, 33(3),379-396. 
Earley, P (1998) School Improvement after Inspection? School and LEA Responses (London, Paul Chapman).

Espinoza, J (2015, July 10th) Schools 'hiring consultants to improve inspection results, The Daily Telegraph. Available at http://www.telegraph.co.uk/education/educationnews/11751201/Schools-hiringconsultants-to-improve-inspection-results.html (accessed January 2017)

Evans, L (2001) Developing Teachers in a Performance Culture - is performance pay the answer? In D. Gleeson and C. Husbands (Eds) The Performing School: Managing Teaching and Learning in a Performance Culture (London, Routledge), 101-107.

Foucault, M (1973) The Birth of the Clinic: An Archaeology of Medical Perception (London, Routledge).

Foucault, M. (1977) Discipline and Punish: The Birth of the Prison (Harmondsworth, Penguin).

Foucault, M. (1988). The Care of the Self: Volume 3 of The History of Sexuality. (New York, Vintage Books).

Foucault, M. (1994). The subject and power. In Faubion, J. D (Ed) Power. Essential Works of Foucault 1954-1984, (London, Penguin), 326-348.

Foucault, M. (2008). The Birth of Biopolitics: Lectures at the College de France 1978-1979 (New York, Palgrave)

Gillies, D. (2013) Educational Leadership and Michel Foucault (London, Routledge)

Grek, S and Lindgren, J. (2014). Governing by Inspection (London, Routledge)

Gustaffson, J-E, Ehren, MCM, Conyngham, G, McNamara, G, Altrichter, H (2015). From inspection to quality: Ways in which school inspection influences change in schools Studies in Educational Evaluation 47(3), 47-57

Harland, J. (1996) Evaluation as Realpolitik. In D. Scott \& R. Usher (Eds) Understanding Educational Research (London, Routledge).

Harris, A., James, S., Gunraj , J., Clarke, P. \& Harris, B. (2006). Improving Schools in Exceptionally Challenging Circumstances (London, Continuum).

Heaton, J. (1998) Secondary analysis of qualitative data Social Research Update 22 http://sru.soc.surrey.ac.uk/SRU22.html

James, C. (1999) Institutional Transformation and Educational Management. In T. Bush, L. Bell, R. Bolam, R. Glatter and P. Ribbins (Eds) Educational Management: Redefining Theory, Policy and Practice (London, Paul Chapman).

Jeffrey, B. (2002). Performativity and Primary Teacher Relations, Journal of Education Policy, 17(5), 531-536. 
Keddie, A. (2013) Thriving amid the performative demands of the contemporary audit culture: a matter of school context Journal of Education Policy 28 (6), 750-766

Lawn, M. Baxter, J. Grek, S and Segerholm, C. (2015) "The new local: system shifts and school inspection”. In Grek, S and Lindgren, J (Eds) Governing by Inspection (London, Routledge), 96-115.

Maguire, M., Perryman, J., Ball, S.J. and Braun, A. (2011) The Ordinary School what is it? British Journal of the Sociology of Education 32 (1), 1-16

Page, D. (2017) The surveillance of teachers and the simulation of teaching, Journal of Education Policy, DOI: 10.1080/02680939.2016.1209566

Perryman, J. (2006) Panoptic performativity and school inspection regimes: disciplinary mechanisms and life under special measures". Journal of Education Policy, 21(2),147-161.

Perryman, J. (2009) Inspection and the fabrication of professional and performative processes Journal of Education Policy 24 (5), 609-629

Plowright, D. (2007) Self-evaluation and Ofsted Inspection: Developing an Integrative Model of School Improvement Educational Management Administration and Leadership, 35 (3), 373-393.

Procter, M. (1993) Analysing Survey Data. In N. Gilbert (Ed) Researching Social Life (London, Sage), 239-254.

Sammons, P., Hillman, J. \& Mortimore, P (1995) Key Characteristics of Effective Schools; a review of School Effectiveness Research. (London, Institute of Education and OfSTED).

Troman, G. (1997) Self-Management and School Inspection: complementary forms of surveillance and control in the primary school Oxford Review of Education, 23(3): 345-363. 